\title{
La economía y las modalidades de la urbanización en México: 1940- 1990
}

Crescencio Ruiz Chiapetto El Colegio de México

\section{Introducción}

En este trabajo propongo que las modalidades que ha experimentado la urbanización de nuestro país en los últimos cincuenta años, están asociadas -en mayor o menor medida- a los avatares de la economía mexicana.

La revisión de los cambios de la economía y de la urbanización parece indicar que, en el periodo 1970-1990, la descentralización de la población se originó por el auge petrolero, y continuó con la crisis de los ochenta.

La economía mexicana: un horizonte de crisis recurrentes

La historia reciente de la economía mexicana, en sus diferentes periodos, ha recibido calificativos ingeniosos, ahora ya convencionales: "milagro mexicano", "docena trágica", "modelo neoliberal”, etcétera. En este apartado sigo la nomenclatura utilizada por Gollás (1994) para narrar los cambios experimentados en la economía mexicana. Él señala cinco periodos a los que bautiza como lecciones. 
Primera lección: el desarrollo estabilizador

Durante cuarenta años (1940-1980), el producto bruto por habitante en México creció a una tasa anual de 3.1 por ciento. En estos años el tipo de cambio se mantuvo fijo, hubo amplia libertad cambiaria, y hasta principios del decenio de 1970, la inflación fue muy baja. Al periodo comprendido entre 1950 y finales de 1960 se le conoció como la etapa del desarrollo "estabilizador".

La estrategia de crecimiento fue la política de sustitución de las importaciones al amparo de la protección estatal. Los rasgos característicos de esta política fueron: $a$ ) elevado proteccionismo; $b$ ) generosidad en los subsidios a la industria; $c$ ) fuertes concesiones fiscales a la importación de bienes de capital; y $d$ ) un alto contenido importado de la producción manufacturera (García Rocha, Gómez-Galvarriato y Romero, 1988).

Por estos años, tanto el crecimiento demográfico como la concentración de la población fueron muy intensos; pero como la economía presentaba tasas de crecimiento mayores que las de la población, existía una gran confianza en los hacedores de las políticas. Con el tiempo, una estructura por edad extremadamente joven, junto a un crecimiento industrial insuficiente en las grandes urbes, generaron una profunda desigualdad económica y social.

\section{Segunda lección: el populismo}

La disminución en el crecimiento de la economía en los primeros años de la década de 1970 condujo a cambios sustanciales en la política fiscal. Durante la administración de Luis Echeverría (19711976), con el propósito de satisfacer demandas populares sin modificar la estructura de la producción, el gasto público se ejerció con demasiada soltura.

Este gasto produjo un incremento en el déficit fiscal que se financió -principalmente- mediante préstamos extranjeros, sin alterar la tasa de cambio. Estas medidas tuvieron como consecuencia: a) un aumento en el déficit de cuenta corriente de la balanza de pagos (de 0.9 mil millones de dólares en 1971, cambió a 4.4 mil millones en 1975); b) la deuda externa creció de 6.7 mil millones de dólares en 1971, a 15.7 mil millones de dólares en 1975 ; y c) la tasa de inflación, de 3.4 por ciento en 1969 , pasó a 17 por ciento en 1975 (Gollás, 1994). 
La forma de conducir la economía era insostenible. En 1976 comienza a manifestarse una fuga de capitales que el Gobierno trata de amortiguar mediante más préstamos del extranjero, y usando las reservas monetarias. Estas políticas sólo agudizaron los problemas: en ese mismo año el peso se devaluó en 40 por ciento, la producción disminuyó su crecimiento en forma drástica, y la inflación fue en aumento. Por primera vez en 20 años el Gobierno mexicano acudió a la ayuda del Fondo Monetario Internacional.

\section{Tercera lección: el derroche}

La recesión de 1976 duró poco; pronto se descubrieron reservas petroleras que liberaron a la economía de las restricciones financieras externas. Con el auge petrolero se estimuló el crecimiento dirigido por el gasto público, lo que dio lugar a los resultados esperados: el producto interno bruto, el empleo y la inversión crecieron a tasas elevadas.

Las expectativas del Gobierno de obtener mayores ingresos por el petróleo (de 1978 a 1981 el precio del petróleo aumentó de 13 a 30 dólares por barril) indujeron a un mayor gasto. Con el tiempo, el efecto de un elevado déficit público y un peso sobrevaluado, fue un desequilibrio en la balanza de pagos (Gollás, 1994). Para finales de 1981, el déficit total del sector público era más de 14 por ciento del Producto Interno Bruto (PIB), y como su financiamiento se hizo con base en préstamos extranjeros, la deuda externa aumentó de 26 a 34 mil millones de dólares entre 1978 y 1980.

Por otra parte, las exportaciones no petroleras tuvieron un crecimiento muy bajo, lo que unido al déficit fiscal, incrementó la demanda de bienes importados, situación que se reflejó en el crecimiento del déficit comercial. Entre 1978 y 1980 pasó de 1.8 mil millones de dólares, a 3.4 mil millones de dólares (Lustig, 1994).

Al mismo tiempo, la inflación por arriba de la mundial, sumada a un cambio fijo, significó una sobrevaluación insostenible del tipo de cambio real. En 1982 la caída en el precio del petróleo y la enorme sobrevaluación del peso elevaron las expectativas de devaluación. Las tasas de interés reales eran negativas, lo cual provocó una voluminosa fuga de capitales que produjo el colapso cambiario (García Rocha, Gómez-Galvarriato y Romero, 1988). 
Para entonces resultaba ya imposible mantener la tasa de cambio mediante préstamos externos, por lo que el peso se devaluó de 26 a 45 pesos por dólar. En agosto de 1982 las reservas casi se habían agotado, la fuga de capitales continuaba, y se había interrumpido el flujo de préstamos del exterior, lo que llevó a otra devaluación.

En ese mismo agosto el gobierno federal nacionalizó la banca privada, y en diciembre de ese año México declaró la moratoria al pago principal de su deuda externa. Esto provocó el cierre de flujos de crédito externo, el cese de las inversiones privada y pública, y una fuga de capitales sin precedente (Gollás, 1994; y García Rocha, Gómez-Galvarriato y Romero, 1988).

\section{Cuarta lección: las bases del ajuste}

La nueva administración comenzó su periodo enfrentando una aguda crisis económica. Las tareas heredadas exigían corregir los enormes desajustes fiscales y monetarios, además de la negociación con los acreedores bancarios internacionales. Con este propósito, en diciembre de 1982 Miguel de la Madrid anunció un plan de estabilización: PIRE (Programa Inmediato de Reorganización de la Economía). La instrumentación de este plan en 1983, se tradujo en una reducción sin precedente del gasto público.

El déficit primario, que representaba 7.6 por ciento del PIB en 1982, en 1983 se convierte en superávit de 4.4 por ciento. La oferta monetaria también disminuyó durante este periodo, y el grueso de los ajustes presupuestales fue a costa de la inversión pública. La inflación de casi 100 por ciento en 1982, bajó a 80.8 por ciento en 1983, y a 59.2 por ciento en 1984.

A pesar de la contracción en la demanda, el tipo de cambio tuvo que ajustarse para permitir una subvaluación que redujera el saldo comercial y fomentara las exportaciones. Esta depreciación del tipo de cambio real tuvo los efectos esperados; la balanza comercial en 1982 alcanzó un superávit de 6 mil millones de dólares, después de un déficit del mismo monto en 1981. En 1983 el superávit fue de 13.3 millones de dólares, y en 1984 de 12.4 (Gollás, 1994).

En 1985 comenzó el proceso de restructuración industrial que consistió básicamente en eliminar subsidios y abrir la economía a la competencia externa. En ese año México ingresó al GATT (Acuerdo General sobre Aranceles Aduaneros y Comercio), y se registró un aumento sin precedente de las exportaciones manu- 
factureras. Desafortunadamente, en 1985 y 1986 hubo fuertes choques de oferta. (El terremoto de septiembre de 1985, y una caída brusca en el precio del petróleo en 1986). Fue necesario depreciar una vez más el tipo de cambio, lo que causó un fuerte descenso en el salario real y un aumento en la inflación. En 1985 ésta fue de 63.7 por ciento, y en 1986 llegó a 105.7 por ciento (García Rocha, Gómez-Galvarriato y Romero, 1988).

Por otra parte, ante la crisis provocada por la disminución de los precios del petróleo, el país estuvo en 1986 a punto de declarar una moratoria de pagos. Ante esta perspectiva, los bancos internacionales, con poco entusiasmo, acordaron cooperar con el Plan Brady, mediante el cual se le prestaron a México 6 mil millones de dólares y se renegoció 83 por ciento de la deuda (Gollás, 1994).

En 1987 los precios del petróleo comenzaron a recuperarse, pero la inflación no cedió a pesar de la restricción de la demanda. La elevada inflación provocó el desplome del tipo de interés real, y la reducción del crédito condujo a un auge en los mercados secundarios de crédito. Durante este año la Bolsa de Valores fue muy promisoria, hasta que declinó bruscamente en el mes de octubre, cuando cayeron las Bolsas del resto del mundo. Con esta experiencia los inversionistas cambiaron la composición de su cartera a favor de activos denominados en dólares. Las autoridades monetarias percibieron este hecho como un posible ataque especulativo, y con el objeto de proteger las reservas internacionales, decidieron retirarse del mercado cambiario. El anuncio del Banco de México provocó una devaluación especulativa que desató niveles inflacionarios altos. La inflación en 1987 llegó a 159.2 por ciento (García Rocha, Gómez-Galvarriato y Romero, 1988).

Ante estas circunstancias, se puso en marcha un plan heterodoxo con el fin de lograr la estabilidad de precios. El eje central de este plan consistía en un acuerdo entre el Gobierno y los sectores obrero, campesino y empresarial, de no subir precios ni exigir demandas excesivas. Es decir, tomar medidas que requerían de los agentes económicos -obreros, campesinos, empresarios y Gobierno- aceptar pérdidas en forma explícita y concentrada. A este acuerdo se le bautizó como el Pacto de Solidaridad Económica (PSE), que después, en 1988, cambio de nombre a Pacto para la Estabilidad y el Crecimiento Económico (PECE), vigente hasta 1994. 
Para lograr el objetivo de una menor inflación, el PSE fijó como meta disminuirla en 2 por ciento mensual. Otras metas fueron: reducir el déficit fiscal, continuar con la liberación del comercio, y establecer una política de ingresos (control de precios y salarios). El Gobierno se comprometió a mantener fijos la tasa de cambio y los precios de los bienes públicos; el sector privado, por su parte, a no aumentar los precios de bienes y servicios (Gollás, 1994).

El Pacto produjo buenos resultados de inmediato. Durante el segundo semestre de 1988, la inflación fue de sólo 1.2 por ciento (obviamente menor al 9 por ciento registrado en el mismo periodo de 1987). En 1988 el PIB creció a 1.3 por ciento, las exportaciones no petroleras a 15.2 por ciento, y la inversión privada a 10.9 por ciento.

Pero, el control de la inflación no se reflejó en un crecimiento sustancial del producto. La disciplina fiscal era esencial para recuperar y mantener la estabilidad financiera y de precios, pero también tenía efectos desalentadores sobre la inversión privada. El gobierno de Salinas, que llegó al poder en 1988, afrontó el desafío de terminar con ese estancamiento.

\section{Quinta lección: la modernización}

El primer paso del gobierno de Carlos Salinas de Gortari (19881994) fue anunciar el Pacto para la Estabilidad y el Crecimiento Económico (PECE). En él se destaca el compromiso del Gobierno con la recuperación del crecimiento sin sacrificar la estabilidad de precios. Parte importante de la política económica consistía en recuperar los capitales mexicanos que habían salido del país, por lo que era necesario ganar la confianza del sector privado nacional y extranjero.

Reducir las transferencias de recursos al exterior exigía concentrar los esfuerzos en tres objetivos: disminuir la carga del servicio de la deuda, alentar la repatriación de capitales, y atraer la inversión extranjera. Para estos propósitos era fundamental convencer al Gobierno de Estados Unidos de que la política económica mexicana prometía seriedad y eficacia. Las buenas negociaciones condujeron a que el Gobierno estadounidense decidiera poner en práctica el llamado Plan Brady, orientado a reducir el monto y servicio de la deuda de aquellos países elegibles. México fue el primer país en solidarizarse con ese Plan (Lustig, 1994). 
A pesar de ese acuerdo (Plan Brady), el ahorro y las entradas de capital no fueron sustanciales. El gobierno de Salinas tomó entonces dos medidas espectaculares: a) en 1990 reprivatizó los bancos, lo que provocó que el flujo de capitales hacia México creciera y que las tasas de interés disminuyeran; y $b$ ) se iniciaron las negociaciones para un Tratado de Libre Comercio (TLC, o NAFTA, por sus siglas en inglés) entre Estados Unidos, Canadá y México. Estas medidas restablecieron la confianza del sector privado en el Gobierno y en la economía. De enero a septiembre de 1991 el monto del flujo de capitales hacia México fue de alrededor de 154 mil millones de dólares.

En la administración de De la Madrid se dieron los primeros pasos para privatizar las empresas paraestatales, pero fue el gobierno de Carlos Salinas el que llevó a cabo esa medida hasta sus últimas consecuencias, vendiendo o cerrando la mayoría de las empresas del Estado. En 1983 el Gobierno controlaba o era propietario de 1155 empresas; en 1988, 130 se habían vendido al sector privado, 526 se habían liquidado, y 496 aún estaban en manos del Gobierno, o estaban en proceso de cerrarse o de venderse. Paralelo al programa de "privatización", el Gobierno instrumentó un programa de "desregulación" cuyo objetivo era disminuir los trámites y trabas burocráticas a la actividad productiva privada (Gollás, 1994).

Parecía, en 1991, que la economía había arrancado. En ese año la inflación fue de 18 por ciento y el crecimiento de la economía de 3.6 por ciento. El entusiasmo por los primeros logros del "nuevo" modelo de desarrollo se hizo letra impresa en los estudios de especialistas en la economía mexicana. Nora Lustig, por ejemplo, dice:

[...] el caso de México ilustra cómo la austeridad fiscal, la reducción del salario real y la adopción del menú completo de reformas sugerido por las instituciones de Bretton Woods pueden ser insuficientes para activar la recuperación económica... Este tipo de medidas se expresó en México en la decisión del gobierno de buscar un acuerdo de libre comercio con los Estados Unidos. Esta iniciativa, aunada a la reprivatización de los bancos, contribuyó a modificar la imagen de México en los mercados externos y en las expectativas de los empresarios de forma contundente y en consecuencia aumentaron las entradas de capital privado y se posibilitó la recuperación (Lustig, 1994:86).

Y de manera exagerada, Pedro Aspe declara: 
Existen razones para ser optimistas ante el futuro porque sabemos que fuimos capaces de crecer con estabilidad en el pasado y porque los resultados alcanzados hasta ahora nos han demostrado que el esfuerzo del ajuste y la confianza entre todos los sectores de la sociedad mexicana pueden realmente traducirse en proceso económico y social [...] Hoy en día, la sociedad civil y su gobierno, democráticamente más fuerte y al mismo tiempo más ágil, están encontrando una nueva vitalidad y determinación para tener un proceso todavía mayor, con nuestras aspiraciones firmemente encaminadas hacía un futuro mejor (Aspe, 1993:208-210).

El optimismo no duró mucho; en 1993 la estabilidad de precios marcó un record (la tasa de inflación fue menor a 10 por ciento), pero el crecimiento del PIB fue de sólo 0.4 por ciento; y 1994 estuvo marcado por hechos dramáticos que parecían superados en nuestra historia reciente. El primero de enero de 1994 estalló en el estado de Chiapas el levantamiento armado que cambiaría el futuro político y económico del país, y en marzo de ese año fue asesinado Luis Donaldo Colosio, candidato a la presidencia de la República por el partido oficial, el Revolucionario Institucional (PRI).

A pesar de estos hechos, los pronósticos de la economía para 1994 y 1995 eran optimistas. Incluso las previsiones no oficiales tenían ese carácter. Para una firma extranjera, por ejemplo, el PIB crecería a 2.0 por ciento en 1994 y a 3.5 en 1995; la inflación permanecería en alrededor de 7.5 por ciento en los dos años; la tasa de cambio entre 3.40 y 3.51 nuevos pesos; y las tasas de interés entre 12 y 11 por ciento (Blue Chips Indicators, citado por Gollás, 1994).

Algunos comentaristas sugirieron que esos pronósticos tenían una sombra de maquillaje para mejorar el rostro de las elecciones de la presidencia de la República, pues era difícil aceptar que la reactivación económica pudiera llevarse a cabo justamente cuando el país vivía uno de los momentos financieros, cambiarios y políticos más inciertos de las últimas décadas.

Más allá de las cifras macroeconómicas, la política económica del sexenio de Salinas, a pesar de su aparente éxito, había sido sumamente costosa:

A mediados de 1994 se puede afirmar, con confianza, que el objetivo inicial y más fácil del programa de estabilización, reducir la inflación, ya se cumplió. Ésta ha disminuido como resultado de los acuerdos de la negociación de la deuda externa; de la disminución del déficit público; y del control de algunos precios clave como la tasa de cambio y los 
salarios. Los costos del éxito del programa de estabilización han sido, entre otros, la drástica disminución del crecimiento de la economía, de los salarios reales, del ingreso per cápita y del nivel de vida de la población (Gollás, 1994:37).

\section{Sexta lección: nueva crisis, nuevo ajuste}

En los primeros meses de 1994, la violencia estuvo acompañada de cambios negativos en las variables macro-económicas. La política monetaria de los Estados Unidos (E.U.) comenzó a restructurarse, y parte del capital (en bonos y valores) que había venido a México cuando las tasas interés en E.U. eran bajas, comenzó a retornar a ese país. Para mantener el capital extranjero en México se elevaron las tasas de interés, pero como lo mismo sucedía en E.U., comenzó a disminuir de manera sustancial la inversión en portafolio. Se recurrió entonces a las reservas monetarias para enfrentar los flujos de capital, con el fin de mantener la tasa de cambio.

A esto se agregaba el hecho de que la cuenta corriente en la balanza de pagos empeoraba. Los diferenciales en las tasas de interés en México y en E.U. se ampliaban, y con una tasa de cambio constante en nuestro país, se hacían más atractivos los productos mexicanos a los compradores mexicanos. Por otra parte, la apertura comercial con el Tratado de Libre Comercio favoreció a la competencia extranjera, en términos que algunas compañías mexicanas no podían solventar.

De esta manera, la disminución en el flujo de capital extranjero, el exceso de las importaciones sobre las exportaciones, y la tasa de cambio fija, hacían predecible un impacto negativo en las reservas monetarias. Cuando las reservas comenzaron a caer de una manera abrupta, se emitieron en México bonos de corto plazo (tesobonos) que garantizaban a los inversionistas su reembolso en dólares. En los últimos meses de 1994 la mayor parte de los bonos gubernamentales en manos privadas eran tesobonos.

Las medidas adoptadas (altas tasas de interés, tesobonos) no cambiaron el panorama, las tasas de interés no lograron recuperar las reservas monetarias, el déficit de la cuenta corriente era mayor, y las tasas de interés en E.U. seguían incrementándose. Estos hechos fueron el escenario previo a la devaluación de diciembre de 1994 (Gruben, 1955).

Lo grave de la devaluación se atribuye también a otros factores: a) como en su anuncio inicial se dijo que continuaría la política de deslizamiento del peso a partir de una nueva tasa de 
cambio, y esta medida no se consideró suficientemente confiable, los tenedores de pesos mexicanos continuaron demandando dólares, hasta el punto en que la compra y venta de esta moneda se dejó a las fuerzas del mercado; $b$ ) la proporción elevada de préstamos bancarios no recuperados (cartera vencida) por empresas que no podían competir en un mercado abierto, debido a las dificultades que presentaban un nuevo valor del peso y las crecientes tasas de interés; $\mathrm{y}, c$ ) la inminente convertibilidad en el corto plazo de los tesobonos, amparados en dólares, ejercía una presión externa en la posición de las reservas monetarias en la primera mitad de 1995 (Gruben, 1995; y Sachs, Tornel y Velasco, 1995).

A los pocos días de la devaluación se presenta un Programa de Ajuste (24 de enero de 1995). Historia repetida para los mexicanos: la restricción del gasto público se programa en 1.3 por ciento del PIB, el peso continúa flotando, se limita el crecimiento de la masa monetaria, y el salario mínimo tiene un incremento de sólo 7 por ciento. Los estudiosos de la economía mexicana pronto darán cuenta de los alcances y límites de esas medidas de ajuste. Entonces, los pronósticos para 1995 eran, por demás, desalentadores.

Tres características del repaso hecho hasta aquí me parecen relevantes: a) el predominio, en el análisis, de la esfera financiera por encima de las estructuras productiva y ocupacional; $b$ ) la fuerza de ciclos sexenales en la repetición de crisis y ajustes; y, $c$ ) el surgimiento de nuevos agentes privados en la toma de decisiones de la política económica nacional.

\section{Modalidades de la urbanización: auge y depresión económica}

Con el riesgo de ser excesivamente esquemático, propongo una asociación entre los tiempos de la economía y los tiempos de la urbanización en nuestro país. El desarrollo estabilizador estuvo acompañado de un ritmo intenso de concentración de población en la Zona Metropolitana de la Ciudad de México (1940-1970); luego, los años de la “docena trágica”, no tan trágica para el desarrollo regional, comenzaron a presentar indicios de descentralización de la población, que para algunos autores fue anuncio de una transición urbana (1970-1982); y, finalmente, los nuevos años de crisis-ajuste-crisis continuaron esa descentralización demográ- 
fica por el estancamiento de la economía (1982-1995). Hago referencia a estos periodos.

1. Desarrollo estabilizador y concentración de la población: 19401970

En los años del "milagro mexicano" (1940-1970), como dije antes, la tasa de crecimiento económico de México fue cercana o mayor a 6.0 por ciento anual. En ese periodo, el sector agrícola generó la mano de obra para las ciudades, produjo bienes, salario y materias primas baratas, y con base en los cultivos de exportación, fue la principal fuente de divisas. De 1940 a 1995 la agricultura creció 7.4 por ciento anual y la industria manufacturera 6.9 por ciento, y en el lapso 1955-1970 la agricultura disminuyó su tasa de crecimiento a 3 por ciento anual, por debajo del crecimiento de la población; en cambio, la industria aumentó a 8.6 por ciento anual (Solis, 1970).

Mientras en la economía se hablaba de milagros, en el desarrollo urbano se veían problemas. En los años sesenta y setenta, como se recordará, el panorama de la urbanización, según los especialistas, era alarmante, sobre todo para países menos desarrollados, cuya población se concentraba con una intensidad sin precedente.

Las características atribuidas a la urbanización justificaban esa alarma. Aun cuando la proporción de población urbana en los países de mayor desarrollo había alcanzado un límite que permanecía constante, las grandes ciudades continuaban aumentando de tamaño debido al crecimiento de la población total. Este atributo de la urbanización, su irreversibilidad, fue el elemento esencial de las visiones del desarrollo urbano futuro (ciudades mundiales, áreas megalopolitanas, etcétera) (Scientific American, 1965).

En los países de menor desarrollo las preocupaciones por el crecimiento de la población urbana, y en especial de las zonas metropolitanas, dio lugar a dos temas de estudio: la sobreurbanización, y el alto grado de primacía en la estructura urbana. La formulación del fenómeno de la sobreurbanización, generalmente se presentaba con base en aspectos demográficos o sociales: a) Así, se decía que el alto crecimiento de la población -la caída en la tasa de mortalidad y la persistencia de la alta fecundidad-en la mayor parte de los países de América hispánica, asociados a una intensa concentración de población y a un desarrollo industrial 
poco dinámico, daba lugar a la "sobre-urbanización" o "terciarización” en estos países. De acuerdo con esta idea, puede haber un desequilibrio entre el crecimiento de la población y el crecimiento de la participación del sector industrial en el producto y en la fuerza de trabajo (Friedman y Lackington, 1967; y Sovani, 1964). b) O bien, se comentaba que dentro de la teoría de la modernización, el proceso de migración en la última de sus tres etapas -motivación, canal de traslado y ajuste o desajuste personal en el lugar de destino- podía dar lugar a una masa marginal, ya que, el ajuste o desajuste del migrante rural a la vida urbana, en una sociedad en transición, dependía de la capacidad del individuo para cambiar los roles de una sociedad tradicional (adscripción, particularismo, difusión y afectividad) a los de una sociedad moderna (desempeño, universalismo, especificidad y neutralidad afectiva) (Germani, 1979).

El tema de la terciarización en el desarrollo urbano de México, fue puesto en duda por el hallazgo de algunos estudiosos de la migración a las grandes ciudades. Oliveira (Oliveira, en $\mathrm{Mu}-$ ñoz, Oliveira y Stern, 1977) encontró que la migración a la ciudad de México se había dirigido en una proporción alta al sector secundario y no al terciario. De 1940 a 1959 el sector secundario absorbió un poco más de la tercera parte de los migrantes, y de 1960 a 1969 dio trabajo a más de la mitad de ellos. Este hallazgo se asocia, sin duda, con la época de mayor crecimiento industrial del país.

Los estudios de la primacía en la estructura urbana de los países menos avanzados tomó dos vertientes: una la atribuía a la diferencia entre los países ricos y pobres; otra consideraba que el predominio de una gran ciudad en el sistema de ciudades era consecuencia de las características del capitalismo.

La primera visión asociaba el nivel de desarrollo con los tipos de distribución de población (mayor primacía en los países subdesarrollados y mayor cercanía a la regla rango-tamaño en los países desarrollados) (Berry, 1961). Aunque no pudo comprobarse esta hipótesis, la literatura sobre primacía en esta línea fue extensa. Algunos autores vieron a las grandes ciudades como parasitarias (Hoselitz, 1955); otros identificaron condiciones típicas de países con alta primacía (Linsky, 1965); e incluso se argumentó que el predominio de las ciudades capitales obedecía más a características demográficas que económicas (Richardson y Schwartz, 1988). La solución más cercana a este problema está en el trabajo de El-Shakhs (1972), quien muestra que los países 
aumentaron su primacía en la etapa del despegue de su economía, cuando la concentración de las actividades económicas era condición del arranque de la industrialización; y al llegar la economía a mayor grado de desarrollo comienza a presentarse un fenómeno de descentralización, acompañado de una disminución relativa del predominio de la ciudad capital.

La contraparte a este tipo de literatura proviene de la teoría de la dependencia, que objetaba el supuesto de que todos los países tomaran una pauta similar en su desarrollo. Para los dependentistas, la inserción perférica de los países menos desarrollados en el ámbito internacional los podría destinar a un subdesarrollo permanente. Las bases para explicar la primacía con este enfoque eran históricas y económicas: a) los países con herencia colonial recibieron como secuela estructuras urbanas de alta primacía, pues tanto los países metropolitanos como los coloniales ejercieron su control por medio de las principales ciudades; y $b$ ) las economías de los países pobres están supeditadas a una base exportadora muy débil, pues si el comercio de esas exportaciones requiere sólo de una ciudad, a ella se destinará la infraestructura (vías de comunicación), la inversión y los mejores servicios, con el consecuente deterioro de las localidades de menor tamaño (Smith, 1985).

En nuestro país, la preocupación por la primacía de la ciudad de México ha estado presente en buena parte de la literatura sobre desarrollo urbano. El crecimiento demográfico de la Zona Metropolitana de la Ciudad de México (ZMCM) fue explosivo durante los años 1940-1970. En estas décadas, cuando la economía experimentaba un desarrollo sostenido, la población de la ZMCM más que se cuadruplicó. En 1940 era de 1.9 millones de habitantes, y en 1970 aumentó a 9.0 millones. En estas tres decadas la tasa de crecimiento de la población fue mayor a 5 por ciento. El incremento extraordinario en el volumen de la población de la ZMCM se refleja también en su participación respecto a la del total del país: en 1940 fue de 9.9 por ciento, y en 1970 llegó a 18.6 por ciento.

Cuando aparecieron los datos de población de la ZMCM para 1970 , y con base en éstos se elaboraron proyecciones para décadas posteriores, las reacciones de alarma no se hicieron esperar. La catástrofe parecía un anuncio en el futuro de la ciudad de México: ésta llegaría a ser en el año 2000 la metrópoli más poblada del mundo. Esta visión de la ciudad de México alimentó a los estudios urbanos, que en el decenio de los años setenta esta- 
ban fuertemente influidos por conceptos de la economía política. Para esos estudiosos, la concentración de población en las grandes ciudades se debía a características inherentes al capitalismo; en los países con esa modalidad productiva, las ciudades seguirían aumentando de tamaño de una manera irreversible. A la ZMCM se le auguraba un futuro megalopolitano.

Los datos del Censo de Población de 1980 disminuyeron, en parte, esa visión alarmante. El volumen de la población de la ciudad de México en 1980 fue de 13.9 millones de habitantes, con una tasa de crecimiento de 4.38 por ciento en el periodo 1970-1980. Quizá estos resultados, o quizá la nueva literatura de países avanzados, dio lugar a investigaciones relacionadas con la transición urbana, la descentralización de la población y las ciudades medias.

\section{La "docena trágica" y los inicios de la transición urbana}

En el curso de los años setenta, buen número de países desarrollados tuvieron, por primera vez en su historia industrial, un decrecimiento demográfico de sus grandes metrópolis. La novedad de este fenómeno sustituyó la concepción clásica de la urbanización, que pronosticaba mayores incrementos relativos de la población en las ciudades grandes (Davis 1965; y Simon, 1955).

La experiencia de ese cambio demográfico contrarió al esperado, y originó múltiples estudios sobre la descentralización de lo que algunos autores bautizaron como proceso de "contraurbanización” (Berry, 1976; y Champion, 1989). El claro rompimiento con el pasado (clean break) se manifestaba en el crecimiento poblacional de las ciudades pequeñas, mayor que el de las grandes urbes (Vining y Strauss, 1977), y en el crecimiento autónomo (no megalopolitano) de las ciudades localizadas alrededor de las grandes metrópolis ("reversión de la polarización”) (Richardson, 1980). Preocupaciones afines a este tema produjeron estudios aplicables a países de menor nivel de desarrollo. Alonso (1980), por ejemplo, sugiere que el desequilibrio en el progreso de un país en sus primeras etapas de desarrollo, disminuye en etapas posteriores de industrialización. Según Alonso, varios procesos sociales toman la forma de campana en el tiempo: las etapas de desarrollo, la desigualdad social, las disparidades regionales, la concentración geográfica (primacía), y la transición demográfica. Wheaton y Shishido (1981), por su parte, asocian -en un modelo logístico- la disminución en la concentración de 
la población con un determinado nivel de desarrollo. Cuando este último llega a los 2000 dólares per cápita, las economías de algomeración de la gran ciudad dejan de funcionar y se presenta una incipiente descentralización de la población.

La base teórica de esa literatura fue expuesta por primera vez en un artículo de Zelinsky (1971), quien supone cinco etapas de desarrollo, durante las cuales la migración rural-urbana manifiesta un comportamiento en forma de campana. Las etapas intermedias se caracterizan por migraciones masivas que van decreciendo conforme el país avanza en su desarrollo. Es decir, las transferencias de población de las zonas rurales a las urbanas, de manera similar a la transición demográfica, aumentan y disminuyen de acuerdo con el desarrollo económico (transición urbana). Al aplicar este modelo a México, Ledent (1981) encontró que la tasa de migración rural-urbana del país en 1980, estaba en el punto más elevado, por lo que consideró que después de ese punto la tendencia creciente de la migración se revertiría.

Los datos del Censo de Población de 1980 -como se dijo antes- mostraban una incipiente descentralización de la población. La ciudad de México, en el periodo 1970-1980, había disminuido su velocidad de crecimiento demográfico en comparación con el decenio 1960-1970, y más de diez ciudades (con población mayor de 100000 habitantes en 1980) experimentaron una tasa mayor que las grandes metrópolis del país (más de 5 por ciento anual).

Estos cambios en la distribución de la población fueron interpretados de distinta manera; para algunos autores se trataba de indicios que anunciaban grandes cambios (transición urbana, despegue de las ciudades medias, reversión de la polarización, etcétera) (Graizbord, 1984; Negrete y Ruiz, 1991; Velázquez y Arroyo, 1992; y Chávez, 1995); para otros, la gran atracción de la ZMCM continuaría en los años por venir, por lo que era de esperar un crecimiento megalopolitano (Garza y Partida, 1988; y Garza y Rivera, 1993).

Con los años, las administraciones de los presidentes Echeverría y López Portillo han sido severamente criticadas; la herencia que dejaron, esos doce años, en el sistema financiero, más que justifican las críticas. Pero, durante esos dos sexenios la economía mexicana manifestó cambios claramente positivos. El crecimiento del PIB mantuvo una tasa mayor a 6 por ciento anual (de 1970 a 1975 el PIB tuvo una tasa de crecimiento anual de 6.26 por ciento; de 1976 a 1977 disminuyó a 3.8 por ciento anual; y, 
de 1978 a 1981, alcanzó una tasa de 8.4 por ciento anual), y nuestro país cruzó el umbral de los 2000 dólares pér capita necesarios para la descentralización de la población según el modelo de Wheaton y Shishido. El ingreso per cápita en 1975 fue de 2276 dólares, y en 1980 llegó a 2578 dólares (precios internacionales de 1975) (Summers y Heston, 1984). Desde esta perspectiva, los resultados del Censo de 1980 se convirtieron en un anuncio claro de la disminución en la fuerza de atracción de población de la ZMCM.

Como se sabe, los resultados del Censo de Población de 1990 mostraron una disminución sustancial en el crecimiento demográfico de la ZMCM. De 1980 a 1990 su tasa de crecimiento fue de sólo 0.64 por ciento anual. Si ese dato es cierto, prácticamente todas las ciudades intermedias crecieron más que la ciudad de México. Con base en esa cifra podría pensarse que la transición urbana tomó carta de ciudadanía en el crecimiento de las ciudades del país; pero, es conveniente aclarar que, si bien México había llegado a un nivel de desarrollo considerable en 1980, los años posteriores a la "docena trágica" fueron escenario de una crisis económica severa, por lo que la disminución en la concentración de población de 1980 a 1990 deberá explicarse por razones económicas diferentes a lo ocurrido en el decenio 1970-1980.

\section{Crisis económica y descentralización de la población}

La "contra-urbanización" no fue duradera. Los primeros datos de los Censos de Población de 1980 en los países desarrollados -específicamente Estados Unidos- mostraron que la caída en el crecimiento demográfico de las grandes ciudades en el periodo 1970-1980, no continuó en el quinquenio 1980-1985. Las grandes metrópolis del noreste de E.U. (Nueva York, Filadelfia y Boston) que habían experimentado tasas de crecimiento negativas en el decenio 1970-1980, tuvieron un crecimiento positivo después de ese periodo. Un comportamiento semejante se presentó en las grandes ciudades de países europeos.

Dos estudios fundamentales (Vining y Pallone, 1982; y Cochrane y Vining, 1988) apoyaron la explicación de varios autores a estos nuevos fenómenos. La migración a las áreas periféricas de las regiones centrales (metrópolis) parecían sólo un acontecimiento pasajero que ocurre cuando se exigen nuevos requisitos en la localización espacial de la población por ajustes en la eco- 
nomía (Cochrane y Vining, 1988). El surgimiento y la caída de la contraurbanización se debían entonces a fuerzas económicas y demográficas que daban lugar a la desconcentración de la población y a la restructuración de las regiones (Champion, 1988). Para Frey (1988) los años ochenta no indicaban un retorno a la alta urbanización, ya que las tasas de crecimiento de las ciudades en ese periodo fueron sustancialmente menores que en la década 1960-1970. Mera (1988) encuentra que, en Japón, fueron las medidas conservadoras de la política económica (desregulación y privatización) las que contribuyeron a la reconcentración de la urbanización en los ochenta; y Berry (1988) busca una explicación de mayor alcance temporal, ubicando los cambios de la urbanización en la teoría de los ciclos económicos de larga duración.

Geyer y Kontuly (1993) proponen una teoría (urbanización diferencial) que busca explicar los elementos característicos de la desconcentración de la población ("reversión de la polarización", "clean break" y "contra-urbanización”) y el retorno a la urbanización. Suponen ellos ciclos urbanos en los que el predominio en el crecimiento demográfico (las tasas más altas) corresponde primero a las ciudades grandes, luego a las medianas, y al final a las pequeñas. Terminado este ciclo comenzará otro con las mismas características. Urbanización-contraurbanización-urbanización, etcétera, marcan los puntos de auge y depresión en los ciclos de la concentración de la población.

Considerar ciclos en la urbanización lleva a revisar los modelos que ven en los procesos de desarrollo el comportamiento de una forma de campana (Williamson, 1965; Zelinsky, 1971; y Alonso 1980), pues en ellos no se establece con claridad la relación que puede darse entre una crisis económica y la concentración y desconcentración de la población.

México, en los años ochenta, experimentó una profunda crisis económica. De 1982 a 1988 el crecimiento del PIB fue de sólo 0.2 por ciento, los salarios reales disminuyeron sustancialmente su poder adquisitivo, el gasto público se contrajo, y la inflación llegó en algunos de esos años a los tres dígitos. Esta crisis, sin duda, detuvo el desarrollo regional incipiente de los años setenta, afectando especialmente a los grupos de población de menores ingresos. A partir de estas consideraciones, es posible pensar que al agravarse los factores de rechazo en los lugares de origen de la población, la migración rural-urbana sería más intensa. Por otra parte, los datos económicos indicaban que las entidades con 
mayor grado de desarrollo eran las más afectadas por la caída de la economía. La literatura sobre el tema es breve, pero muy clara: los ciclos económicos en sus etapas de auge dan lugar a mayores flujos migratorios, y en épocas de depresión los disminuyen (Thomas, 1954; Lee, 1969; y Schultz, 1945).

Los datos del Censo de Población de 1990 se dieron a conocer con una rapidez desacostumbrada (a menos de cinco meses de su levantamiento se publicaron los datos preliminares). Las cifras no esperadas para la población del país, y para el Distrito Federal, provocaron reacciones desfavorables al nuevo Censo. La población asignada al total del país fue de 81.1 millones de habitantes (con un valor muy por abajo del señalado por las proyecciones), y el dato de la población del Distrito Federal (8.2 millones de habitantes) era menor que el del Censo de 1980. Con las cifras de 1990, la ZMCM sólo habría aumentado en 900 mil habitantes en los años ochenta. De 13.8 millones de habitantes en 1980, a 14.7 millones de habitantes en 1990, con una tasa de crecimiento de 0.64 por ciento anual.

Esta caída de la ciudad de México en la estructura urbana sólo podría explicarse por un subconteo sustancial de la población de la capital del país en el levantamiento del Censo de 1990. Pero hay indicios de una fuerte emigración de los habitantes del Distrito Federal a las ciudades medias durante el periodo 19801990 (CONAPO, 1987; Negrete, 1990; y Negrete, Graizbord y Ruiz, 1993), por lo que es difícil llegar a una conclusión cierta sobre el monto de población de la ciudad de México. Podemos decir que parece existir una clara tendencia de descentralización demográfica en el centro del país, aunque no sabemos su magnitud exacta.

Aun dejando de lado los datos del Censo de 1980, y tomando sólo los datos de la población de 1970 y 1990, la tasa de crecimiento de la ZMCM es sustancialmente menor que la de las ciudades intermedias. En esos 20 años la ZMCM creció a una tasa de 2.25 por ciento anual, y diez ciudades medias (mayores de 100000 habitantes en 1980) tuvieron un crecimiento mayor de 3.5 por ciento anual.

Si estamos interesados en asociar los cambios en la descentralización de la población con factores económicos, podemos suponer -a manera de hipótesis- que la disminución en la velocidad del crecimiento demográfico de la ZMCM en el periodo 19701990 se produjo por condiciones económicas diferentes. De 1970 a 1980, por un impulso del gasto público en la inversión produc- 
tiva que se reflejó tanto en el incremento del PIB per cápita nacional (en este decenio se cruzó el umbral de los 2000 dólares, precios de 1975), como en el impulso a proyectos de desarrollo regional. De 1980 a 1990, la crisis económica y los programas de ajuste condujeron a una disminución del PIB per cápita nacional (en 1980 el PIB per cápita fue de 4342 dólares, y en 1985 pasó a 3985 dólares, precios internacionales de 1980) (Summers y Heston, 1988), lo que desalentó la migración a las grandes ciudades, pues fueron ellas las que recibieron el peor impacto por la caída de la economía.

Sin duda, esta forma excesivamente esquemática de atribuir a dos factores económicos diferentes, y hasta contrarios, la descentralización de la población, debe tomarse con reserva. Será necesario profundizar en la investigación de la urbanización y la economía para conocer el alcance de esta hipótesis.

\section{Bibliografía}

Alonso, W. (1980), "Five Bell Shapes in Development", Papers and Proceedings of the Regional Science Association, vol. 45 , pp. 5-16.

Aspe Armella, P. (1993), El camino mexicano de la transformación económica, México, Textos de Economía, FCE.

Berry, B. J. (1961), "City Size Distribution and Economic Development", Economic Development and Cultural Change, vol. 9, pp. 573-587.

- (1976), "The Counter Urbanization Process-Urban American Since 1970", en B. J. Berry, Urbanization and Counter Urbanization, vol. 11, Urban Affairs Review, Londres, Sage, pp. 17-30.

— (1988), "Migration Reversals in Perspective: The Long Wave Evidence”, International Regional Science Review, vol. 11, núm. 3, pp. 245-251.

Cochrane, S. G. y D. R. Vining Jr. (1988), "Recent Trends in Migration Between Core and Pheripheral Regions in Developed and Advanced Developing Countries", Interna- 
tional Regional Science Review, vol. 11, núm. 1, pp. 215243.

Consejo Nacional de Población (1987), Características principales de la migración en las grandes ciudades del país. Resultados preliminares de la Encuesta Nacional de Migración en Áreas Urbanas (ENMAU), México, CONAPO.

Champion, A. G. (1988), "The Reversal of the Migration Turnaround: Resumption of Traditional Trends?", International Regional Science Review, vol. 11, núm. 3, pp. 253260.

- (1989) (ed.), Counter Urbanization. The Changing Pace and Nature of Population Deconcentration, Londres, E. Arnold.

Chávez, A. M. (1995), "Un nuevo horizonte de la migración en el centro de México", Estudios Demográficos y Urbanos, vol. 10, núm. 2 (29), pp. 295-345.

Davis, K. (1965), “The Urbanization of the Human Population”, Scientific American, núm. 213, pp. 41-53.

El-Shakhs, S. (1972), "Development Primacy and System of Cities", The Journal of Developing Areas, vol. 7, pp. 11-36.

Frey, W. H. (1988), "The Re-emergence of Core Region Growth: A Return to the Metropolis?", International Regional Science Review, vol. 11, núm. 3, pp. 261-267.

Friedmann J. y T. Lackington (1967), "Hyperurbanization and National Development in Chile: Some Hypothesis", Urban Affairs Quarterly, núm. 4, pp. 3-29.

García Rocha, A., A. Gómez-Galvarriato y J. Romero (1988), "Evolución de la economía mexicana: 1940-1988", documento elaborado para el $v$ Encuentro Hispano-Mexicano de Científicos Sociales, México. 
Garza, G. y V. Partida (1988), "Hacia la superconcentración espacial”, Demos, Carta Demográfica de México, núm. 4, pp. 11-12.

Garza, G. y S. Rivera (1993), “Desarrollo económico y distribución de la población urbana en México, 1960-1980”, Revista Mexicana de Sociología, año LVI, núm. 1, enero-mayo, (1/93), pp. 177-212.

Germani, G. (1979), Urbanización, desarrollo y modernización, Buenos Aires, Paidós.

Geyer, H. S. y T. Kontuly (1993), "A Theoretical Foundation for the Concept of Differential Urbanization", International Regional Science Review, vol. 15, núm. 2, pp. 157-177.

Gollás, M. (1994), "México 1944: Una economía sin inflación, sin igualdad y sin crecimiento", Documento de Trabajo, núm. XI, Centro de Estudios Económicos/El Colegio de México, septiembre, pp. 1-659.

Graizbord, B. (1984), "Perspectivas de una descentralización en México: Propuesta de análisis”, Revista Interamericana de Planificación, vol. XVIII (7), pp. 36-58.

Gruben, W. C. (1995), “The Peso and Mexico's Financial Crisis”, Research Department, Federal Reserv Bank of Dallas, 12 de enero.

Hoselitz, B. F. G. (1955), “Generative and Parasitic Cities”, Economic Development and Cultural Change, vol. 3, pp. 278294.

Ledent, J. (1981), "Rural-Urban-Migration, Urbanization and Economic Development", Economic Development and Cultural Change, vol. 30, pp. 17-30.

Lee, E. (1969), “A Theory of Migration”, en J. A. Jackson (comp.), Migration, Cambridge University Press, pp. 287-297. 
Linsky, A. S. (1965), "Some Generalizations Concerning Primate Cities", Annals of the Association of American Geographers, vol. 55, pp. 506-513.

Lustig, N. (1994), México. Hacia la reconstrucción de una economía, México, El Colegio de México-FCE.

Mera, K. (1988), “The Emergence of Migration Cycles?, International Regional Science Review, vol. 11, núm. 3, pp. 269-275.

Muñoz, H., O. De Oliveira y C. Stern (comps.) (1977), Migración y desigualdad social en la ciudad de México, México, Instituto de Investigaciones Sociales/unam-El Colegio de México.

Negrete, M. E. (1990), "La migración a la ciudad de México", Estudios Demográficos y Urbanos, vol. 5, núm. 3 (15), pp. 641-654.

— y C. Ruiz (1991), "Perfil demográfico y urbano de la ciudad de México: Indicios pequeños de cambios grandes”, en U. Oswald y J. Serrano (coords.), Ciudad de México: Recursos para su alimentación, Cuernavaca, México, Centro Regional de Investigaciones Multidisciplinarias (CRIM)/ UNAM, pp. 119-188.

—, B. Graizbord y C. Ruiz (1993), Crecimiento demográfico y evolución espacial de la Zona Metropolitana de México, México, Programa de Estudios Avanzados en Desarrollo Sustentable y Medio Ambiente (LEAD-México)/El Colegio de México.

Richardson, H. W. (1980), "Polatization Reversal in Developing Countries", Papers and Proceedings of the Regional Science Association, vol. 45, pp. 67-85.

— y G. Schwartz (1988), "Economic Development, Population and Primacy", Regional Studies, vol. 22, pp. 467-475.

Sachs, J., A. Tornel y A. Velasco (1995), “The Collapse of the Mexican Peso: What Have we Learned?”, Working Paper 
No. 5142, Cambridge MA., Natural Bureau of Economic Research, Inc.

Scientific American (1967), núm. 213, 1965 (Número dedicado al proceso de urbanización). Traducción al español: Scientific American, La ciudad, Madrid, Alianza Editorial.

Schultz, T. W. (1945), Agriculture in an Unstable Economy, Nueva York, Mac Graw Hill.

Simon, H. A. (1955), "On a Class of Skew Distribution Functions", Biometrika, vol. 42, partes 3 y 4, diciembre, pp. 425-440.

Smith, C. A. (1985), "Theories and Measures of Urban Primacy: A Critique", en M. Timberlake (comp.), Urbanization in the World Economy, Londres, Academy Press, Cap. 6, pp. 87-117.

Solís, L. (1970), La realidad económica mexicana: Retrovisión y perspectiva, México, Siglo XXI.

Sovani, S. V. (1964), "The Analysis of Over Urbanization”, Economic Development and Cultural Change, vol. 12, pp. 113-122.

Summers, R. y A. Heston (1984), "Improved International Comparisons of Real Product and its Composition: 19501980", Review of Income and Wealth, Serie 30, núm. 2, junio, pp. 207-262.

— (1988), "A New Set of International Comparisons of Real Product and Price Levels Estimates for 130 Countries, 1950-1985", The Review of Income and Wealth, Serie 34, núm. 1, pp. 1-25.

Thomas, B. (1954), Migration and Economic Growth. A Study of Great Britain and the Atlantic Economy, Inglaterra, Cambridge University Press.

Velázquez, L. A. y J. Arroyo A. (1992), "La transición de los patrones migratorios y las ciudades medias", Estudios De- 
mográficos y Urbanos, vol. 7, núms. 2 y 3 (20-21), pp. 555-574.

Vining, D. R. y A. Strauss (1977), "A Demonstration That the Current Deconcentration in the Unites States is a Clean Break With the Past", Environment and Planning, vol. 9, pp. 751-758.

Vining, D. R. y R. Pallone (1982), "Migration Between Core and Pheripheral Regions: A Description and Tentative Explanation of the Pattern in 22 Countries", Geoforum, vol. 13, núm. 4, pp. 339-410.

Wheaton, W. C. y H. Shishido (1981), "Urban Concentration, Agglomeration Economies and the Level of Economic Development", Economic Development and Cultural Change, vol. 30, pp. 17-30.

Williamson, J. W. (1965), "Regional Inequality and Process of National Development: A Description of the Patterns", Economic Development and Cultural Change, vol. 13, pp. $3-45$.

Zelinsky, W. (1971), "The Hypothesis of the Mobility Transition”, Geographical Review, vol. 61, pp. 219-249. 